\title{
Auditory Psychophysics
}

National Cancer Institute

\section{Source}

National Cancer Institute. Auditory Psychophysics. NCI Thesaurus. Code C18637.

Studies of the interactions between mind and physiology in relation to hearing perception. 